\title{
Levofloxacin-ceftazidime administration regimens combat Pseudomonas aeruginosa in the hollow-fiber infection model simulating abnormal renal function in critically ill patients
}

\author{
L Zhao, X Li, X He (iD and L Jian ${ }^{*}$
}

\begin{abstract}
Background: The purpose of this study was to investigate the bactericidal effects of levofloxacin and ceftazidime as both monotherapy and combination therapy, and to determine their effects on resistance suppression in patients with normal and abnormal (Ccr:16-20 mL/min) renal function. Common clinical administration regimens to provide reference values were further evaluated.

Methods: The 7-d hollow-fiber infection model was used to inject the Pseudomonas aeruginosa standard strain (ATCC27853), which simulated common clinical administration regimens for patients with different renal function. Ten regimens were stratified into 2 categories based on renal function, and each category contained 3 monotherapy regimens and 2 combination therapy regimens. Total and resistant populations were quantified. Drug concentrations were determined by high-performance liquid chromatography (HPLC).

Results: Monotherapy regimens resulted in about $0.5-\mathrm{log}-\mathrm{CFU} / \mathrm{mL}$ bacterial kill in the total population at 6 or $8 \mathrm{~h}$, whilst combination regimens resulted in 2- to $3-\mathrm{log}-\mathrm{CFU} / \mathrm{mL}$ within 2 days. For levofloxacin monotherapy regimens in patients with normal renal function, resistance emergence was seen after $6 \mathrm{~h}$, and was seen at $0 \mathrm{~h}$ in the ceftazidime monotherapy regimen, as well as in all regimens of patients with abnormal renal function. Although resistant subpopulation in combination regimens with abnormal renal function began to increase at $0 \mathrm{~h}$, there was a definite downward trend after $8 \mathrm{~h}$, while resistant population in the normal renal function group increased after $16 \mathrm{~h}$.
\end{abstract}

Conclusions: Combination therapy had greater bactericidal efficacy and resistance inhibition compared with monotherapy. Studying combination regimens in randomized clinical trials is warranted.

Keywords: Levofloxacin, Ceftazidime, Hollow-fiber infection model, Renal function, Pseudomonas aeruginosa

*Correspondence: hexj@sj-hospital.org; jianly@sj-hospital.org

Department of Pharmacy, Shengjing Hospital of China Medical University,

Shenyang 110004, China

C C The Author(s). 2020 Open Access This article is licensed under a Creative Commons Attribution 4.0 International License, which permits use, sharing, adaptation, distribution and reproduction in any medium or format, as long as you give appropriate credit to the original author(s) and the source, provide a link to the Creative Commons licence, and indicate if changes were made. The images or other third party material in this article are included in the article's Creative Commons licence, unless indicated otherwise in a credit line to the material. If material is not included in the article's Creative Commons licence and your intended use is not permitted by statutory regulation or exceeds the permitted use, you will need to obtain permission directly from the copyright holder. To view a copy of this licence, visit http://creativecommons.org/licenses/by/4.0/ The Creative Commons Public Domain Dedication waiver (http://creativecommons.org/publicdomain/zero/1.0/) applies to the data made available in this article, unless otherwise stated in a credit line to the data. 


\section{Background}

$P$. aeruginosa is a common conditional pathogen of hospital acquired pneumonia, especially in patients in intensive care units (ICUs) who require respiratory support [1]. Abnormal renal function is common in ICUs patients. Doses of antibacterial therapy need to be adjusted for ICUs patients. This is explained by the kidney is the main organ for drug elimination, so without dose adjustment, the accumulation of drugs and their metabolites in plasma would increase the possibility of toxicity [2]. At present, the resistance to $P$. aeruginosa is increasing [3]. About $15 \%$ of $P$. aeruginosa strains are resistant to at least three-fifths of antimicrobial agents with an antipseudomonal spectrum (ceftazidime, fluoroquinolones, piperacillin/tazobactam, carbapenems and aminoglycosides), and $5 \%$ are resistant to all 5 according to data from the European Centre for Disease Prevention and Control [4]. Combined with clinical practice, the main cause of bacterial resistance is the unreasonable use or even abuse of antibacterial drugs. In the process of exploring how to reasonably use antibiotics and reduce bacterial resistance, the establishment of the in vitro hollow-fiber infection model (HFIM) has become an important research method.

Yadav et al. [5] used HFIM to optimize the combination of piperacillin and tobramycin, and their research showed that optimized combination regimens brought out effective bacterial kill and inhibition of resistance emergence in patients with augmented renal clearance. Jumbe et al. [6] demonstrated that levofloxacin can inhibit amplification of resistant subpopulations when the AUC/MIC (area under the concentration-time curve at $24 \mathrm{~h}$ divided by minimum inhibitory concentration) ratio reaches 157 . However, in patients treated with $750 \mathrm{mg}$ levofloxacin once daily, when Monte Carlo simulation was used to detect the frequency of achieving this ratio in the distribution of levofloxacin MIC values, only $61 \%$ were able to reach it. In a meta-analysis including 17 studies, Vardakas et al. [7] demonstrated that the combination of levofloxacin and $\beta$-lactam increased the bacterial kill rate for community acquired pneumonia.

Therefore, it is important to explore combination therapy for rapid bacterial kill and inhibition of amplification of resistance. We explored the clinically relevant 7-day administration period of levofloxacin and ceftazidime against the $P$. aeruginosa standard strains using the HFIM.

\section{Methods}

\section{Microorganisms and antimicrobials}

This study was conducted in accordance with the Declaration of Helsinki. P. aeruginosa ATCC27853 was provided by the Laboratory of Shengjing Hospital affiliated to China Medical University, Shenyang,
China. The strain was stored at $-70^{\circ} \mathrm{C}$. Levofloxacin (Daiichi Sankyo, batch number: BS099N1) and ceftazidime (GlaxoSmithKline, batch number: 16120020) were obtained from the Shengjing Hospital Pharmacy department.

\section{Susceptibility studies}

The MIC was defined as the minimum concentration of drug that led to invisible growth after incubation at $37^{\circ} \mathrm{C}$ for $24 \mathrm{~h}$. The MICs of levofloxacin and ceftazidime for $P$. aeruginosa ATCC27853 were resolved by using the agar dilution and broth microdilution methods described by the Clinical and Laboratory Standards Institute (CLSI) [8]. The MPC (mutation preventive concentration) was determined at $72 \mathrm{~h}$ by using of agar dilution methods. Different concentrations of MHA (Mueller Hinton agar) plates containing levofloxacin and ceftazidime separately were prepared. The drug concentrations were combined in a checkerboard method $(n=3)$. The fractional inhibitory concentration (FIC) value was determined by the minimum concentration of levofloxacin and ceftazidime without visible growth after $24 \mathrm{~h}$ of incubation at $37^{\circ} \mathrm{C}$.

\section{High-performance liquid chromatography (HPLC) methods}

A validated HPLC method was used to determine concentrations of levofloxacin and ceftazidime in samples acquired from the central reservoir. The column used was an Agilent ZORBAX SB-C18 (4.6 mm × 150 $\mathrm{mm}$, particle size $5 \mu \mathrm{m})$. For levofloxacin, the mobile phase included $0.05 \mathrm{~mol} / \mathrm{L} \mathrm{K}_{2} \mathrm{HPO}_{4}$ (containing $0.3 \%$ triethylamine, adjusted to $\mathrm{PH} \approx 3$ by phosphoric acid) and acetonitrile (volume ratio $=89: 11$ ). The UV detector was used at $295 \mathrm{~nm}$, column temperature was $30{ }^{\circ} \mathrm{C}$, flow rate was $1 \mathrm{~mL} / \mathrm{min}$, injection amount was $50 \mu \mathrm{L}$. For ceftazidime, the mobile phase included $0.05 \mathrm{~mol} / \mathrm{L} \mathrm{K}_{2} \mathrm{HPO}_{4}$ (adjust to $\mathrm{PH} \approx 5.8$ by triethylamine) and methanol (volume ratio $=80: 20$ ). The UV detector was used at $254 \mathrm{~nm}$, column temperature was $30^{\circ} \mathrm{C}$, flow rate was $1 \mathrm{~mL} / \mathrm{min}$, injection amount was $50 \mu \mathrm{L}$.

\section{Hollow-fiber infection model}

Blaser [9] described the HFIM as a pharmacodynamic system for bacteria, and Bilello [10] introduced its schematic and description. In the current study, levofloxacin and/or ceftazidime were instilled into the central reservoir every $8 \mathrm{~h}$ (ceftazidime) or every day (levofloxacin). The infusion time was 60 or $90 \mathrm{~min}$ for levofloxacin, and $30 \mathrm{~min}$ for ceftazidime. In experiments where the 2 drugs were used at the same time, the half-lives of levofloxacin (about 6.4 h) and ceftazidime (about $1.9 \mathrm{~h}$ ) were quite different, which was solved by the approach of 
Blaser [11]. MHB (Mueller Hinton broth, no drug) was instilled into the central reservoir from the diluent reservoir to dilute the drug, simulating the elimination of the drug in vivo. Partial MHB-containing drugs were taken out from the central reservoir simultaneously to maintain an equal volume system. Bacteria were inoculated and limited into the outside of capillary of the hollow fiber, and exposed to the fluctuating drug concentration in the central reservoir through an internal cyclic pump in the system.

\section{Dosage regimens and pharmacokinetic(PK) studies}

The inoculum was prepared by a medium-sized colony of $P$. aeruginosa growing in MHB in a $37^{\circ} \mathrm{C}$ on a constant temperature shaker at $200 \mathrm{r} / \mathrm{min}$ overnight to logarithmic growth phase. The appropriate amount of bacterial solution was diluted to $1-2 \times 10^{7} \mathrm{CFU} / \mathrm{mL}$ and inoculated into a HFIM. There were ten experimental groups and 1 control group. Initial experiments were conducted to simulate common regimens for patients with normal renal function. For levofloxacin monotherapy, doses of 500 and $750 \mathrm{mg}$ daily were administered as a 60 and $90 \mathrm{~min}$ infusion. For ceftazidime monotherapy, a total dose of $3 \mathrm{~g}$ was given as 1 g every $8 \mathrm{~h}$, administered as $30 \mathrm{~min}$ infusions. The combination regimens were as follows. The 500 and $750 \mathrm{mg}$ levofloxacin doses were combined with $1 \mathrm{~g}$ of ceftazidime every $8 \mathrm{~h}$, respectively. The regimens of subsequent experiments were based on renal creatinine clearance. We selected the critically ill patients with Ccr of $16-20 \mathrm{~mL} / \mathrm{min}$ to simulate the regimens. Corresponding regimens were 125 and $187.5 \mathrm{mg}$ levofloxacin daily as 60 and $90 \mathrm{~min}$ infusions, and $1 \mathrm{~g}$ ceftazidime daily as a $30 \mathrm{~min}$ infusions. The 125 and $187.5 \mathrm{mg}$ doses of levofloxacin were combined with 1 $\mathrm{g}$ of ceftazidime daily, respectively. Concentrations of levofloxacin and ceftazidime obtained in the experiment were measured using validated HPLC methods. Samples were taken from the central reservoir at different time points and stored at $-80^{\circ} \mathrm{C}$, then the concentration-time curve was plotted with Graphpad prism 8, and data was analyzed with SPSS 24.0.

\section{Pharmacodynamic (PD) studies}

Bacterial culture samples were taken from the hollowfiber cartridge at different time points. Serially diluted samples were quantitatively cultured onto drug-free MHA plates to count the total number of bacteria. Some bacterial samples were quantitatively cultured onto MHA plates with either levofloxacin at $5 \times$ and $10 \times$ MIC or ceftazidime at $5 \times$ and $10 \times$ MIC, or a combination of the 2 drugs at $1 \times$ and $2 \times \mathrm{FIC}$ for $P$. aeruginosa ATCC27853, to assess the impact of each regimen on the resistant populations. MHA plates were incubated at $37^{\circ} \mathrm{C}$ for $24 \mathrm{~h}$ before the results were read. Timesterilization curves were then drawn, compared with Graphpad prism 8 and the data were analyzed with SPSS24.0.

\section{Results}

\section{Susceptibility study results}

The MICs for $P$. aeruginosa ATCC27853 were $0.5 \mu \mathrm{g} / \mathrm{mL}$ for levofloxacin and $1.0 \mu \mathrm{g} / \mathrm{mL}$ for ceftazidime. The MPCs for P. aeruginosa ATCC27853 were $5.1 \mu \mathrm{g} / \mathrm{mL}$ for levofloxacin and $82 \mu \mathrm{g} / \mathrm{mL}$ for ceftazidime. The FIC value of levofloxacin combined with ceftazidime was measured to be 1.0 (concentrations of levofloxacin and ceftazidime were $0.25 \mu \mathrm{g} / \mathrm{mL}$ and $0.5 \mu \mathrm{g} / \mathrm{mL}$, respectively).

\section{High-performance liquid chromatography (HPLC) studies}

The retention time for levofloxacin was $6-8 \mathrm{~min}$ and ceftazidime was $8-10 \mathrm{~min}$. The assay of levofloxacin was linear over a range of $1.5625-50 \mu \mathrm{g} / \mathrm{mL} \quad(\mathrm{y}=$ $\left.59.97 x-24.055, r^{2}=0.9998\right)$ and the assay of ceftazidime was linear over a range of $10-320 \mu \mathrm{g} / \mathrm{mL}(\mathrm{y}=$ $\left.0.4659 x+2.9403, r^{2}=0.9999\right)$. The inter-day coefficients of variation for the quality control samples analyzed in triplicate at 3 concentrations on each analysis day ranged from $0.86-2.36 \%$ for levofloxacin and $0.67-1.61 \%$ for ceftazidime. The intra-day coefficients of variation ranged from $0.94-3.75 \%$ for levofloxacin and $0.33-1.46 \%$ for ceftazidime. Accuracies of levofloxacin and ceftazidime were 99.17-102.88\% and $98.97-101.58 \%$, respectively.

\section{Resistant mutation frequency}

For $P$. aeruginosa ATCC27853, the average density of resistant subpopulation at $5 \times$ and $10 \times$ MIC of levofloxacin value was -4.35 and $-3.48 \log \mathrm{CFU}$, respectively. The average density of resistant subpopulation at $5 \times$ and $10 \times$ MIC of ceftazidime was -5.01 and $-4.42 \log$ CFU, respectively. At $1 \times$ and $2 \times$ FIC value, the average densities of resistant subpopulation were -4.21 and -2.96 $\log \mathrm{CFU}$, respectively.

\section{Pharmacokinetic (PK) results}

Typical concentration-time curves for levofloxacin and ceftazidime are shown in Fig. 1a and b. Data for all regimens are available on request.

Pharmacodynamic (PD) studies of monotherapy regimens The monotherapy effects on total and resistant population burdens within 7 days are shown in Fig. 2 (control and normal renal function) and Fig. 3 (abnormal renal function). The bacteria grew well in the untreated growth control arms and reached a bacterial density of $10^{9}$ to $10^{10} \mathrm{CFU} / \mathrm{mL}$ by Day 2 (Fig. 2a). The effects of 

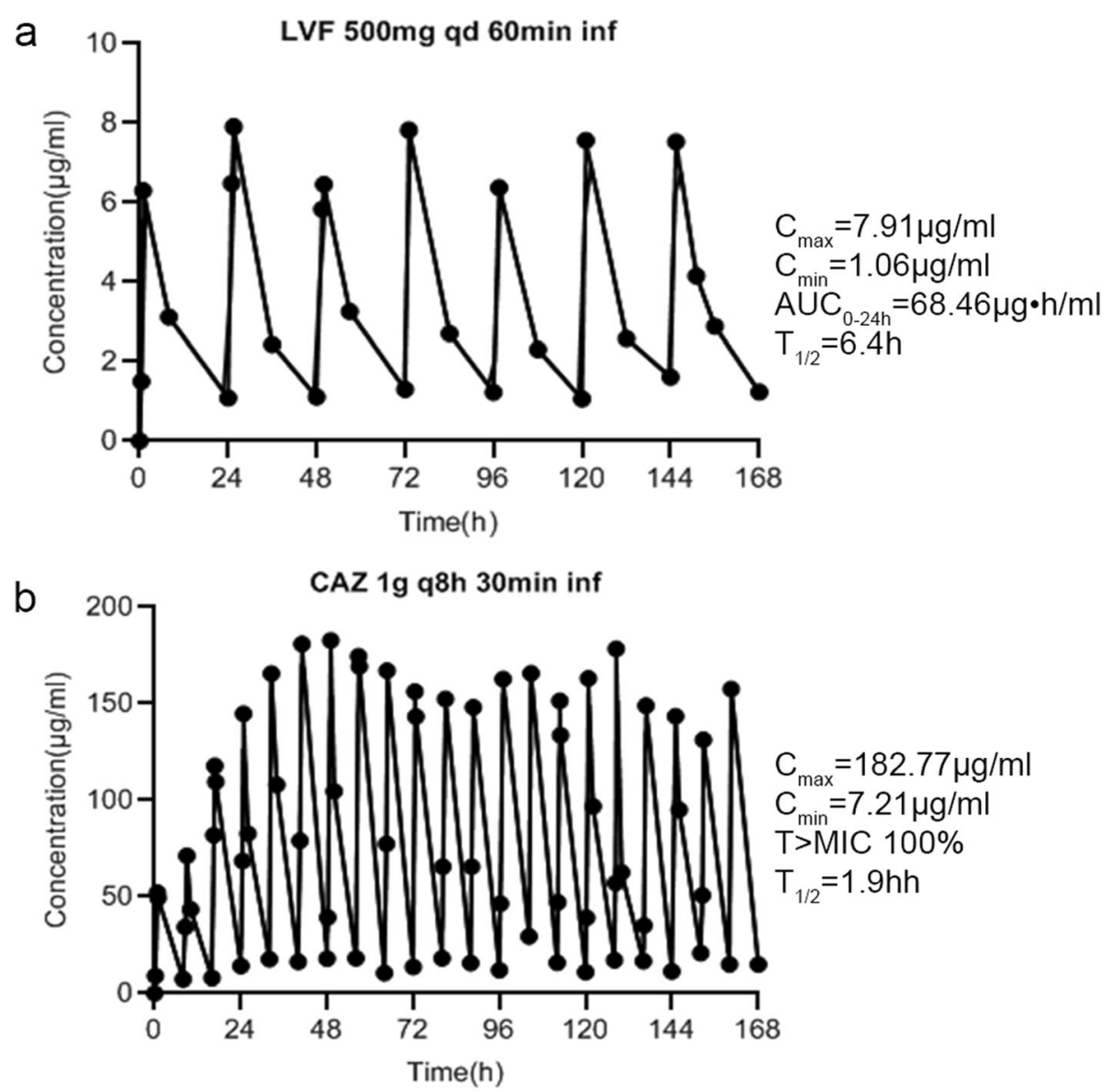

Fig. 1 Various PK simulations in the study. $T_{1 / 2}$, elimination half-life; $A \cup C_{0-24 h}$, area under the concentration-curve from time 0 to $24 \mathrm{~h}$; $C_{\max }$ maximum drug concentration; $C_{\text {min, }}$ minimum drug concentration; $T>M I C$ is the percentage of administration interval. a concentration-time curve of LVF $500 \mathrm{mg}$ qd $60 \mathrm{~min}$ inf; $\mathbf{b}$ : concentration-time curve of CAZ $1 \mathrm{~g}$ q8h $30 \mathrm{~min}$ inf

the levofloxacin and ceftazidime monotherapies for patients with normal renal function on the total and resistant population burdens for P. aeruginosa ATCC27853 are shown in Fig. 2b to d. The levofloxacin and ceftazidime control arms produced around a $0.5-\log -\mathrm{CFU} / \mathrm{mL}$ reduction in the total population before 6 or $8 \mathrm{~h}$; however, resistance was seen after $6 \mathrm{~h}$ for levofloxacin regimens and after $0 \mathrm{~h}$ for ceftazidime. Figure 3 displays the total and resistant population burdens for the levofloxacin and ceftazidime monotherapies for patients with abnormal renal function. The levofloxacin and ceftazidime control arms produced less than a $0.5-\log -\mathrm{CFU} / \mathrm{mL}$ reduction in the total population before 6 or $8 \mathrm{~h}$, and $187.5 \mathrm{mg}$ levofloxacin showed a trend of reducing the total population until $72 \mathrm{~h}$. However, rapid resistance emergence at $0 \mathrm{~h}$ was seen in the 3 regimens. Regeneration in the total number of the 6 monotherapy regimens shown in Fig. 2 and Fig. 3 can be explained by the presence of resistance.
Pharmacodynamic (PD) studies of combination therapy regimens

Figure 4 displays the efficacy of combination therapy on $P$. aeruginosa ATCC27853. There was a major effect of combination therapy, which resulted in a 2- to 3-log$\mathrm{CFU} / \mathrm{mL}$ bacterial kill on the total population. The growth of resistant bacteria was seen after $16 \mathrm{~h}$ in the patients with normal renal function, and at $0 \mathrm{~h}$ in the patients with abnormal renal function. But there was a downward trend after $8 \mathrm{~h}$ in the patients with abnormal renal function. Combination therapy regimens were able to suppress the resistant population amplification.

\section{Comparison of all regimens on total population burdens}

Figure 5a shows the comparison of total population burdens in patients with normal renal function, and Fig. 5b shows the same for patients with abnormal renal function. Combination therapy resulted in a $2-\log -\mathrm{CFU} / \mathrm{mL}$ bacterial kill in patients with normal renal function, and 

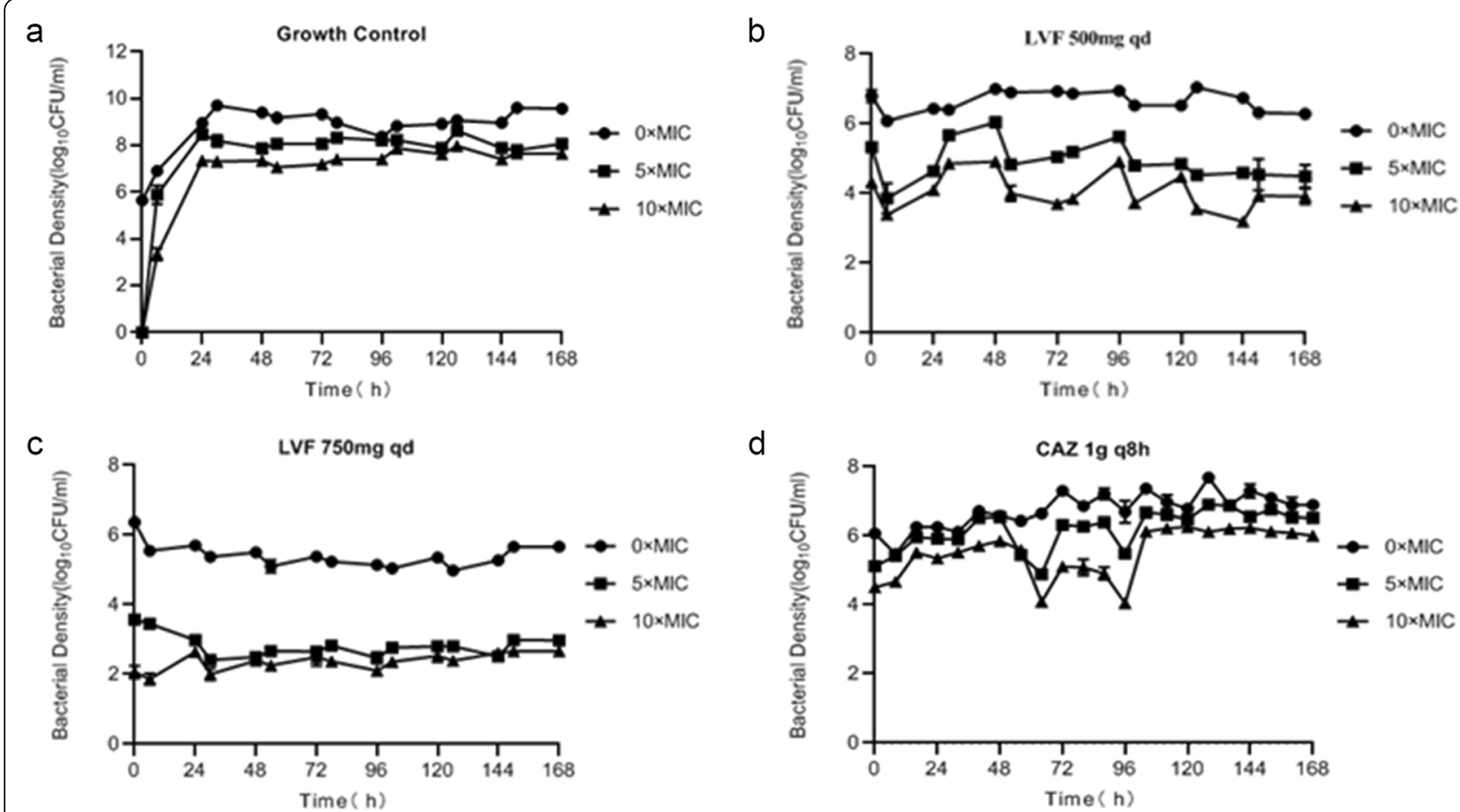

Fig. 2 Observed time-sterilization curve of monotherapy regimens for patients with normal renal function. Data is expressed as the means \pm SD of bacterial burdens. a time-sterilization curve of growth control; $\mathbf{b}$ : time-sterilization curve of LVF $500 \mathrm{mg}$ qd; $\mathbf{c}$ : time-sterilization curve of LVF $750 \mathrm{mg}$ qd; $\mathbf{d}$ : time-sterilization curve of CAZ $1 \mathrm{~g}$ q8h

a 3-log-CFU/mL bacterial kill in patients with abnormal renal function. The results were clearly different from those seen with monotherapy $(p<0.01$, analysis of variance). The comparison also showed that combination therapy was superior to monotherapy in resistance inhibition, because the regrowth in the total population for all regimens was expounded by resistant emergence.

\section{Discussion}

The resistance rate of gram-negative bacteria is increasing. More importantly, it is reported that the multidrug resistance rate is alarmingly high, and steadily increasing $[12,13]$. However, this is not surprising, as our treatment goals previously focused on maximizing clinical and microbiological cure rather than minimizing the emergence of antibiotic resistance [14]. According to the mutation selection window (MSW) theory proposed by Zhao [15], when the drug concentration is higher than the MIC value, antibacterial drugs can play an antibacterial role; however, when the concentration is between MIC and MPC value, while drugs play an antibacterial role, but they can also selectively enrich resistant mutants. Finally, when the concentration is higher than MPC value, resistant mutants must have $\geq 2$ mutations at the same time for selective enrichment to occur.
Therefore, we should not aim to treat patients based on clinical efficacy, but should also consider achieving inhibition of drug resistance on the basis of Zhao's theory.

At present, the situation of bacterial resistance is severe. Luan's study [16] showed that approximately $30 \%$ of $P$. aeruginosa was resistant when older outpatients were infected with community-acquired pneumonia. In a study by Fink et al. [17], monotherapy with $400 \mathrm{mg}$ of ciprofloxacin administered every $8 \mathrm{~h}$ resulted in 33\% resistance to hospital acquired pseudomonas pneumonia, whilst $500 \mathrm{mg}$ of imipenem given every $6 \mathrm{~h}$ or $1000 \mathrm{mg}$ every $8 \mathrm{~h}$ resulted in $50 \%$ resistance. The resistance rate of levofloxacin was $25 \%$ according to a study conducted by Shao Y [18]. In this context, we hope to explore the difference between monotherapy and combination therapy for $P$. aeruginosa.

The traditional combination idea is not to use drug combinations with shared mechanisms of resistance because the orthogonality of resistance probabilities will not hold. The emergence of $\beta$-lactamase (mainly including AmpC, ESBLs, MBLs, etc.) is the main mechanism of $P$. aeruginosa's resistance to $\beta$-lactams [19]. Fluoroquinolones inhibit DNA gyrase (subunit composition: gyrA and gyrB) and topoisomerase IV (subunit composition: parC and parE) of bacteria [20], but the mutation 


\section{a}

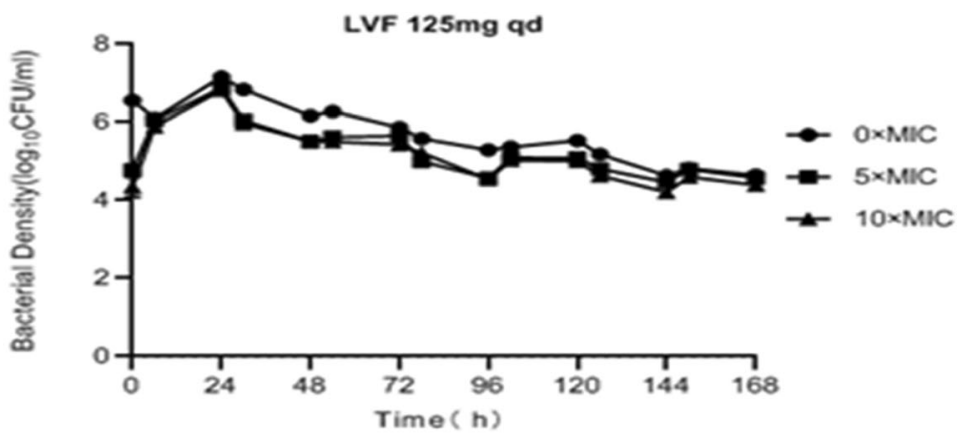

b
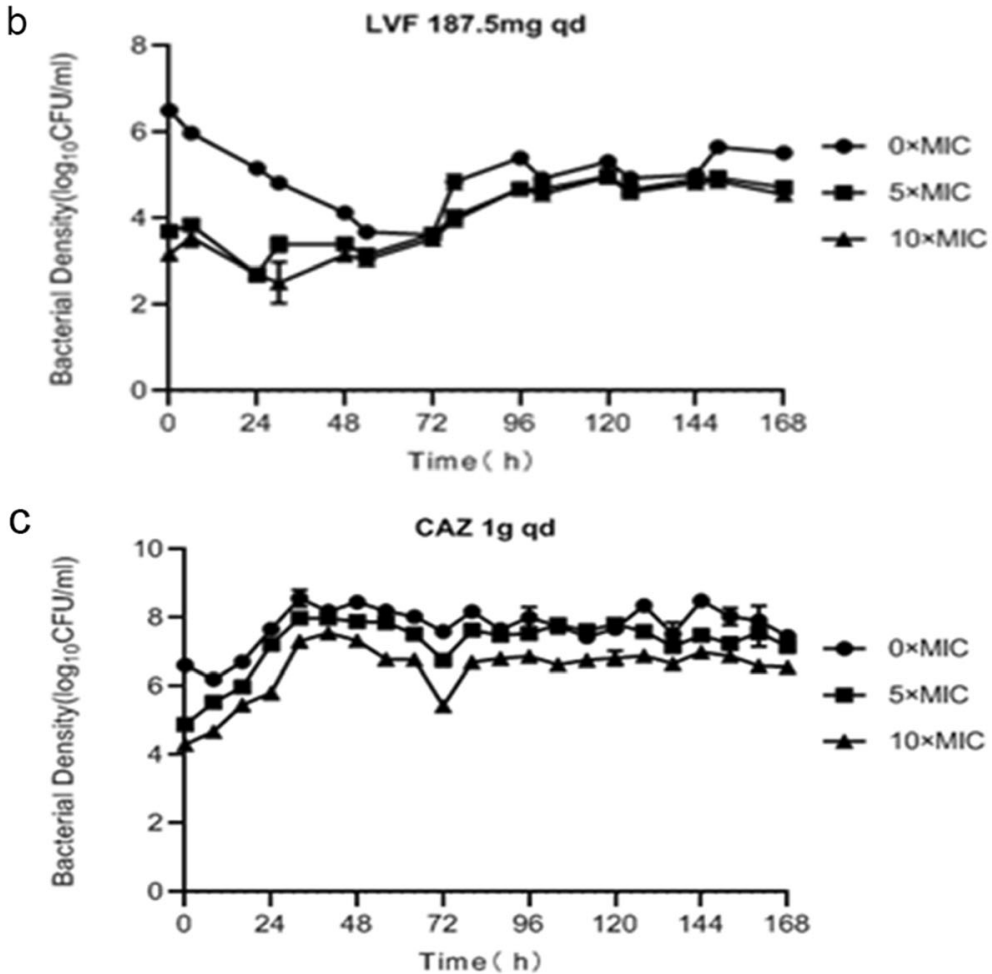

Fig. 3 Observed time-sterilization curve of monotherapy regimens for patients with abnormal renal function. Data is expressed as the means \pm SD of bacterial burdens. $\mathbf{a}$ time-sterilization curve of LVF $125 \mathrm{mg}$ qd; $\mathbf{b}$ : time-sterilization curve of LVF $187.5 \mathrm{mg}$ qd; $\mathbf{c}$ : time-sterilization curve of CAZ $1 \mathrm{~g}$ qd

of any these subunits leads to the resistance of bacteria to fluoroquinolones. As such, we chose to explore the combination of levofloxacin and ceftazidime. Although both drugs are excreted through the kidney, they are very common combination in the clinical treatment of patients with abnormal renal function combined with abnormal liver function and multidrug resistance patients. Up to our knowledge, this study is the first to use a HFIM to investigate the effects of the two drugs on bacterial kill and inhibition of resistance emergence in patients with abnormal renal function. We simulated monotherapy and combination therapy commonly used in clinic, and determined the administration regimens of patients with abnormal renal function according to the instructions. Although there may be some differences in the physiology, sensitivity of bacteria to drugs and binding efficiency of active proteins in HFIM or in vivo and animal studies, our study may better simulate patients with low immune function or without immune system (majority in ICUs) compared with normal patients, and make appropriate references to clinical rational use of drugs.

The PK of levofloxacin or ceftazidime was similar at the same dose in different groups of monotherapy and combination. When $\mathrm{AUC}_{0-24 \mathrm{~h}} / \mathrm{MIC} \geq 100$ and/or $\mathrm{C}_{\max } /$ $\mathrm{MIC}>8$, the bactericidal effect was good for 

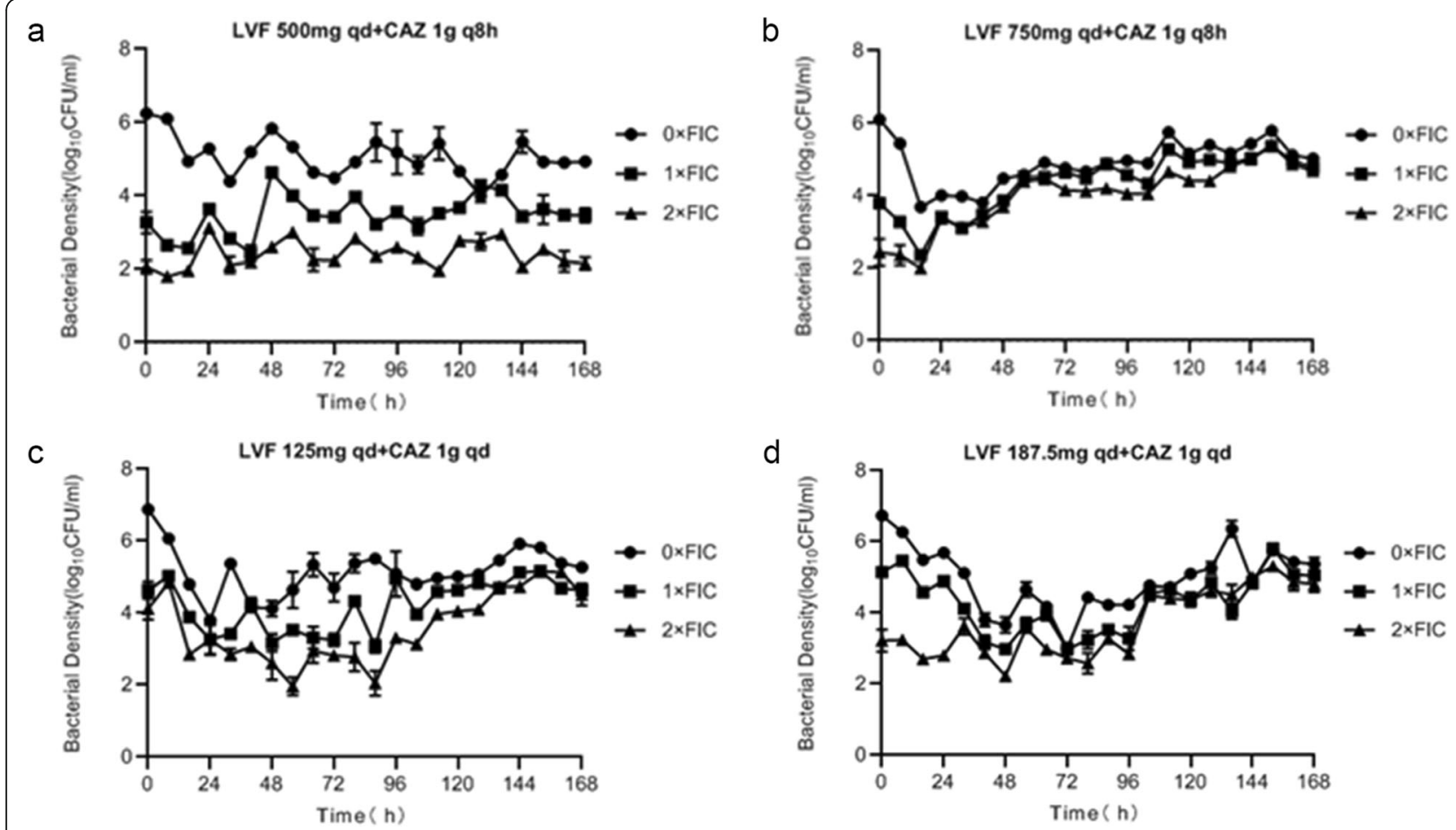

Fig. 4 Observed time-sterilization curve of combination therapy regimens. Data is expressed as the means \pm SD of bacterial burdens. a timesterilization curve of LVF $500 \mathrm{mg}$ qd combined with CAZ $1 \mathrm{~g}$ q8h; $\mathbf{b}$ : time-sterilization curve of LVF 750mg qd combined with CAZ $1 \mathrm{~g}$ q8h; c: timesterilization curve of LVF $125 \mathrm{mg}$ qd combined with CAZ $1 \mathrm{~g}$ qd; $\mathbf{d}$ : time-sterilization curve of LVF $187.5 \mathrm{mg}$ qd combined with CAZ $1 \mathrm{~g}$ qd

fluoroquinolones, and when $\mathrm{T}>\mathrm{MIC}$ is more than $50 \%$, it showed a good bactericidal effect for $\beta$-lactams. However, as observed in some studies [21-23], treatment failure and rapid resistance emergence happened even when $\mathrm{T}>\mathrm{MIC}$ reached or approached $100 \%$ for meropenem, or $\mathrm{AUC}_{0-24 \mathrm{~h}} / \mathrm{MIC}$ was 168 for tobramycin which was 4 times of the suggested breakpoint. So it is necessary in order to find effective ways to inhibit drug resistance. The combination therapy had a better effect on the total and resistant population compared with monotherapy (Fig. 5). The monotherapy produced about a $0.5-\log -\mathrm{CFU} / \mathrm{mL}$ reduction on the total population before 6 or $8 \mathrm{~h}$ (Figs. 2 and 3), while the combination therapy for patients with normal renal function achieved a $2-\log -\mathrm{CFU} / \mathrm{mL}$ bacterial kill on total population, and reduced 3-log-CFU/ml for patients with abnormal renal function within 1-2 days (Fig. 4). Therefore, we can think of this combination as leading to synergistic sterilization. In addition, the effect of bacterial kill on combination therapy in patients with abnormal renal function was superior to that in patients with normal renal function. Because the combination of the two drugs has a potential cross effect on patients' renal burden, this study may be useful for exploring lower doses of levofloxacin combined with ceftazidime to kill bacterial and inhibit resistance in patients with abnormal renal function.

For monotherapy, drug concentration exceeded the MPC value after the first dose when given as 500 or 750 mg levofloxacin once daily, which decreased to less than MPC after $6 \mathrm{~h}$. As such, resistance emergence was seen after $6 \mathrm{~h}$. Drug concentrations of other monotherapy regimens was between MIC and MPC after the first administration, so drugs were able to produce bactericidal effects, but not inhibit resistance, so resistance appeared at $0 \mathrm{~h}$. For combination therapy, the growth of resistant bacteria appeared after $16 \mathrm{~h}$ in patients with normal renal function. In the patients with abnormal renal function, resistance emergence was seen at $0 \mathrm{~h}$, but there was a downward trend after $8 \mathrm{~h}$. Therefore, resistance may be reduced if the dose was increased properly to reach the MPC value at the first administration in patients with normal renal function. For patients with abnormal renal function, if their first dose was equal to that of normal patients, they may obtain better effects of bacterial kill and resistance suppression. Of course, the appropriate administration should be implemented according to patient's Ccr later, and therapeutic drug monitoring should take place. In addition, we suggest priority should be given to combination rather than monotherapy. 

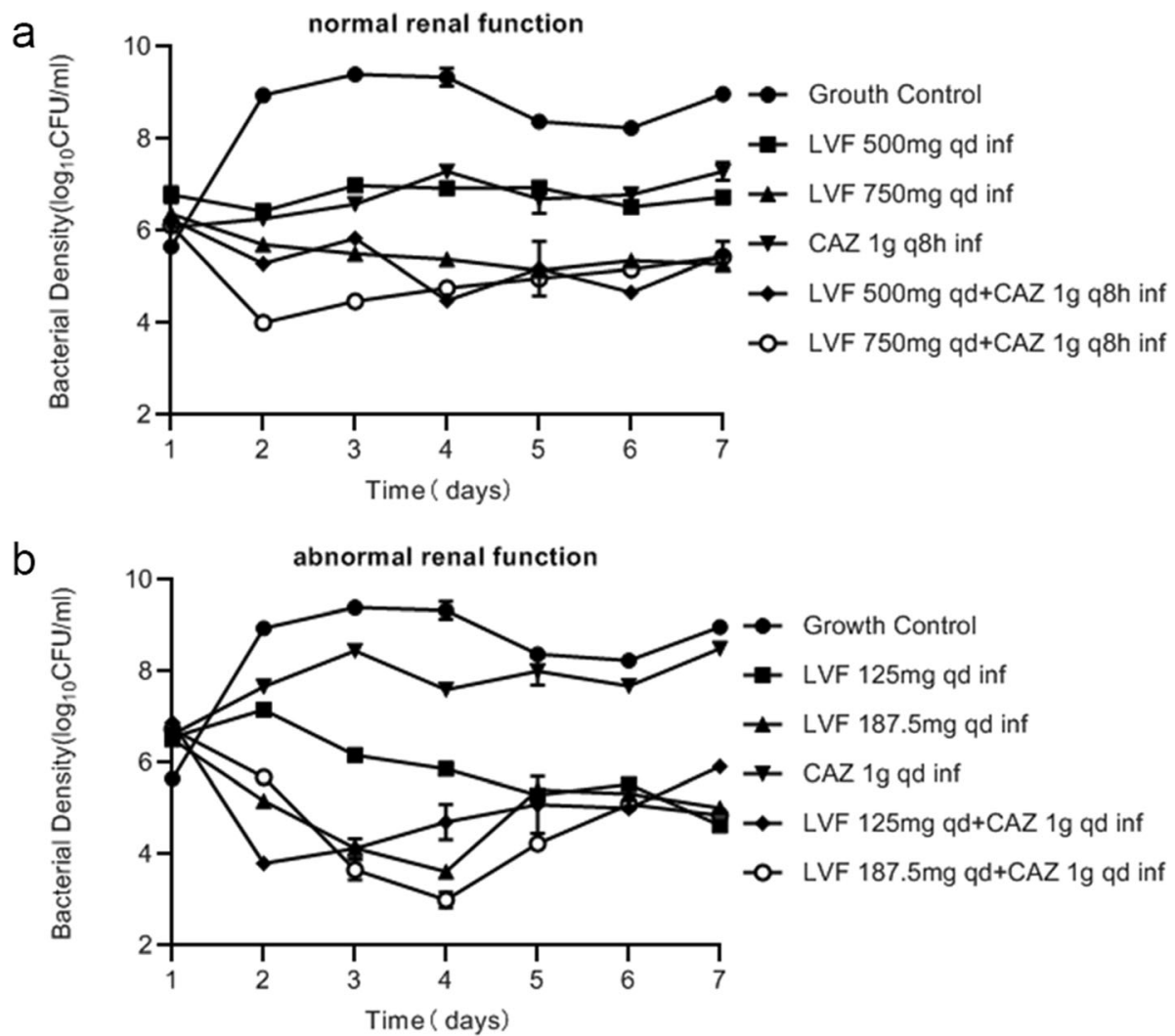

Fig. 5 Comparison of total population burdens on all regimens. Data is expressed as the means \pm SD of bacterial burdens. a comparison of total population burdens in patients with normal renal function; $\mathbf{b}$ : comparison of total population burdens in patients with abnormal renal function

\section{Conclusions}

The combination of levofloxacin and ceftazidime is attractive, and the results of this study suggest their combined effects should be studied in randomized clinical trials to explore the lower doses for sterilization and resistance suppression.

\section{Supplementary information}

Supplementary information accompanies this paper at https://doi.org/10. 1186/s40360-020-0396-5.

\section{Additional file 1.}

\section{Abbreviations}

AUC: Area under the concentration-time curve; CAZ: ceftazidime; CLSI: Clinical and Laboratory Standards Institute; FIC: Fractional inhibitory concentration; HFIM: Hollow-fiber infection model; HPLC: High-performance liquid chromatography; ICUs: Intensive care units; LVF: Levofloxacin; MHA: Mueller Hinton agar; MHB: Mueller Hinton broth; MIC: Minimum inhibitory concentration; MPC: Mutation preventive concentration; MSW: Mutation selection window; PD: Pharmacodynamic PK: Pharmacokinetic; Q8h: Quaque 8 h; Qd: Quaque day

\section{Acknowledgements} Not applicable.
Authors' contributions

$L Z, X L, X H$ and $L$ all contributed to the design and conception of the study. $\mathrm{LZ}$ and $\mathrm{XL}$ primarily completed data collection. $\mathrm{LZ}, \mathrm{XH}$ and $\sqcup$ were involved in the analysis. $\mathrm{LZ}$ and $\mathrm{XH}$ prepared the initial draft with all authors

contributing to critical review. All authors approved the final manuscript.

\section{Funding}

This study was funded by Natural Science Foundation of Liaoning Province, China (Funding Number: CA57). Funder roles were solely sponsoring purchasing research items and consumables.

Availability of data and materials

The datasets used and/or analysed during the current study are available from the corresponding author on reasonable request.

Ethics approval and consent to participate Not applicable.

Consent for publication

Not applicable.

\section{Competing interests}

The authors declared no potential conflicts of interest with respect to the research, authorship, and/or publication of this article.

Received: 7 January 2020 Accepted: 21 February 2020

Published online: 04 March 2020

\section{References}

1. Louie A, Grasso C, Bahniuk N, Van Scoy B, Brown DL, Kulawy R, Drusano GL. The combination of meropenem and levofloxacin is synergistic with respect 
to both Pseudomonas aeruginosa kill rate and resistance suppression. Antimicrob Agents Chemother. 2010;54:2646-54.

2. Hosohata K. Role of oxidative stress in drug-induced kidney injury. Int J Mol Sci. 2016;17:1826-36

3. Eurosurveillance editorial t. ECDC publishes 2014 surveillance data on antimicrobial resistance and antimicrobial consumption in Europe. Euro Surveill. 2015;20

4. Weist K, Diaz Hogberg L. ECDC publishes 2013 surveillance data on antimicrobial resistance and antimicrobial consumption in Europe. Euro Surveill. 2014;19.

5. Yadav R, Rogers KE, Bergen PJ, Bulitta JB, Kirkpatrick CMJ, Wallis SC, Paterson DL, Nation RL, Lipman J, Roberts JA, Landersdorfer CB. Optimization and evaluation of Piperacillin-tobramycin combination dosage regimens against Pseudomonas aeruginosa for patients with altered pharmacokinetics via the hollow-Fiber infection model and mechanism-based modeling. Antimicrob Agents Chemother. 2018;62:e00078-18.

6. Jumbe N, Louie A, Leary R, Liu W, Deziel MR, Tam VH, Bachhawat R, Freeman C, Kahn JB, Bush K, et al. Application of a mathematical model to prevent in vivo amplification of antibiotic-resistant bacterial populations during therapy. J Clin Invest. 2003;112:275-85.

7. Vardakas KZ, Trigkidis KK, Falagas ME. Fluoroquinolones or macrolides in combination with beta-lactams in adult patients hospitalized with community acquired pneumonia: a systematic review and meta-analysis. Clin Microbiol Infect. 2017;23:234-41.

8. Institute CaLS: Methods for dilution antimicrobial susceptibility tests for bacteria that grow aerobically. Approved standard, 11th ed. 2018.

9. Blaser J, Stone BB, Zinner SH. Two compartment kinetic model with multiple artificial capillary units. J Antimicrob Chemother. 1985;15 Suppl A: 131-7.

10. Bilello JA, Bauer G, Dudley MN, Cole GA, Drusano GL. Effect of 2',3'didehydro-3'-deoxythymidine in an in vitro hollow-fiber pharmacodynamic model system correlates with results of dose-ranging clinical studies. Antimicrob Agents Chemother. 1994;38:1386-91.

11. Blaser J. In-vitro model for simultaneous simulation of the serum kinetics of two drugs with different half-lives. J Antimicrobial Chemother. 1985;15 Suppl A:125-30.

12. Crandon JL, Schuck VJ, Banevicius MA, Beaudoin ME, Nichols WW, Tanudra MA, Nicolau DP. Comparative in vitro and in vivo efficacies of human simulated doses of ceftazidime and ceftazidime-avibactam against Pseudomonas aeruginosa. Antimicrob Agents Chemother. 2012;56:6137-46.

13. Tam VH, Schilling AN, Neshat S, Poole K, Melnick DA, Coyle EA. Optimization of meropenem minimum concentration/MIC ratio to suppress in vitro resistance of Pseudomonas aeruginosa. Antimicrob Agents Chemother. 2005:49:4920-7.

14. Abdul-Aziz MH, Lipman J, Mouton JW, Hope WW, Roberts JA. Applying pharmacokinetic/pharmacodynamic principles in critically ill patients: optimizing efficacy and reducing resistance development. Semin Respir Crit Care Med. 2015;36:136-53.

15. Zhao X, Drlica K. Restricting the selection of antibiotic-resistant mutants: a general strategy derived from fluoroquinolone studies. Clin Infect Dis. 2001; 33(Suppl 3):S147-56.

16. Luan $Y$, Sun $Y$, Duan S, Zhao P, Bao Z. Pathogenic bacterial profile and drug resistance analysis of community-acquired pneumonia in older outpatients with fever. J Int Med Res. 2018;46:4596-604.

17. Fink MP, Snydman DR, Niederman MS, Leeper KV Jr, Johnson RH, Heard SO, Wunderink RG, Caldwell JW, Schentag JJ, Siami GA, et al. Treatment of severe pneumonia in hospitalized patients: results of a multicenter, randomized, double-blind trial comparing intravenous ciprofloxacin with imipenem-cilastatin. The severe pneumonia study group. Antimicrob Agents Chemother. 1994:38:547-57.

18. Shao $Y, L u R$, Yang $Y, X u$ Q, Wang B, Ye G. Antibiotic resistance of helicobacter pylori to 16 antibiotics in clinical patients. J Clin Lab Anal. 2018; 32:e22339

19. Khan AU, Maryam L, Zarrilli R. Structure, genetics and worldwide spread of New Delhi Metallo-beta-lactamase (NDM): a threat to public health. BMC Microbiol. 2017:17:101

20. Durcik M, Tomasic T, Zidar N, Zega A, Kikelj D, Masic LP, llas J. ATPcompetitive DNA gyrase and topoisomerase IV inhibitors as antibacterial agents. Expert Opin Ther Patents. 2019;29:171-80.

21. Bergen PJ, Bulitta JB, Kirkpatrick CMJ, Rogers KE, McGregor MJ, Wallis SC, Paterson DL, Nation RL, Lipman J, Roberts JA, Landersdorfer CB. Substantial impact of altered pharmacokinetics in critically ill patients on the antibacterial effects of Meropenem evaluated via the dynamic hollow-Fiber infection model. Antimicrob Agents Chemother. 2017;61:AAC.02642-16.

22. Rees VE, Bulitta JB, Oliver A, Tsuji BT, Rayner CR, Nation RL, Landersdorfer CB. Resistance suppression by high-intensity, short-duration aminoglycoside exposure against hypermutable and non-hypermutable Pseudomonas aeruginosa. J Antimicrob Chemother. 2016;71:3157-67.

23. Ioannides-Demos LL, Liolios L, Wood P, Spicer WJ, McLean AJ. Changes in MIC alter responses of Pseudomonas aeruginosa to tobramycin exposure. Antimicrob Agents Chemother. 1998;42:1365-9.

\section{Publisher's Note}

Springer Nature remains neutral with regard to jurisdictional claims in published maps and institutional affiliations.
Ready to submit your research? Choose BMC and benefit from:

- fast, convenient online submission

- thorough peer review by experienced researchers in your field

- rapid publication on acceptance

- support for research data, including large and complex data types

- gold Open Access which fosters wider collaboration and increased citations

- maximum visibility for your research: over $100 \mathrm{M}$ website views per year

At $\mathrm{BMC}$, research is always in progress.

Learn more biomedcentral.com/submissions 